\title{
Evaluation of Doppler Radar Data for Assessing Depth-Area Reduction Factors for the Arid Region of San Bernardino County
}

\author{
Theodore V. Hromadka II ${ }^{1}$, Rene A. Perez ${ }^{2}$, Prasada Rao ${ }^{3 *}$, \\ Kenneth C. Eke ${ }^{4}$, Hany F. Peters ${ }^{4}$, Col Howard D. McInvale ${ }^{1}$ \\ ${ }^{1}$ Department of Mathematical Sciences, United States Military Academy, West Point, NY, USA \\ ${ }^{2}$ Hromadka \& Associates, Rancho Santa Margarita, CA, USA \\ ${ }^{3}$ Department of Civil and Environmental Engineering, California State University, Fullerton, CA, USA \\ ${ }^{4}$ Flood Control Planning/Water Resources Division, San Bernardino County Department of Public Works, San Bernardino, CA, USA \\ Email: ted@phdphdphd.com, rperez7216@aol.com, *mprasadarao@fullerton.edu, keke@dpw.sbcounty.gov, \\ hpeters@dpw.sbcounty.gov, doug.mcinvale@usma.edu
}

How to cite this paper: Hromadka II, T.V., Perez, R.A., Rao, P., Eke, K.C., Peters, H.F. and McInvale, C.H.D. (2019) Evaluation of Doppler Radar Data for Assessing DepthArea Reduction Factors for the Arid Region of San Bernardino County. Journal of Water Resource and Protection, 11, 217-232. https://doi.org/10.4236/jwarp.2019.112013

Received: January 4, 2019

Accepted: February 25, 2019

Published: February 28, 2019

Copyright $\odot 2019$ by author(s) and Scientific Research Publishing Inc. This work is licensed under the Creative Commons Attribution International License (CC BY 4.0).

http://creativecommons.org/licenses/by/4.0/

\begin{abstract}
The Doppler Radar derived rainfall data for over 150 candidate storms during 1997-2015 period, for the County of San Bernardino, California, was assessed. Eleven most significant storms were identified for detailed analysis. For these significant storms, Depth-Area Reduction Factors ("DARF") curves were developed and compared with the published curves developed and adapted by several flood control agencies for this study area. More rainfall data need to be pursued and analyzed before any correlation hypothesis is proposed.
\end{abstract}

\section{Keywords}

Rainfall, Radar, DARF

\section{Introduction}

The use of Doppler Radar information for rainfall and storm analysis is an evolving technology and is subject to continuing research as to its applications in hydrometeorology and surface water hydrology. An approach being applied in the current study is to use such data for development of correlations between Doppler Radar data and associated aerial extent, and rain gage data and algorithmic estimates of precipitation developed by the National Weather Service ("NWS"), associated with the Radar data. This study approach assembles and identifies peak storm durations of typical key interest in storm hydrometeorology 
and storm runoff hydrology, and then synthesizes the data using GIS technology to estimate area-averaged precipitation accumulated depths versus watershed area coverage. In this way, by examining different peak precipitation durations and corresponding precipitation depths, a correlation to associated Radar data may be examined.

The information corresponding to the candidate storms examined in this study includes Doppler radar data collected from several flood control agencies involved with arid hydrology and located in the southwest regions of the United States. Hundreds of candidate storms were identified and examined for various attributes, resulting in reducing the total population of storms considered. For each candidate storm moved forward in the analysis, various peak duration time-frames (of typical key interest in hydrometeorology and flood control) are examined, and then accumulated precipitation depths were determined versus radar displayed precipitation coverage area.

These accumulated precipitation depth estimates are then plotted against the shown coverage area of the Doppler radar extent as depicted by the radar visualization from the radar stations, resulting in a possible correlation between radar extent and radar estimated precipitation aerial coverage. It is noted that due to the scarcity of precipitation data, Doppler radar data are examined along with the actual precipitation gage data in order to assess possible correlation between these two types of data.

The goal of this study is to assess the possible correlation between the available Doppler Radar data (hereafter, "Doppler data") versus aerial extent relationships (as also estimated by the Doppler data), and the DARF relationships previously derived for these SBC arid areas and also nearby arid regions, by analyzing storms across 18 year period, from 1997 to 2015. The arid portion of San Bernardino County ("SBC") covers approximately 20,000 square miles which are currently monitored by 41 rain gages with hourly or shorter duration data (excluding in this count the daily gauges).

\section{Overview of WSR-88D}

In the following, we briefly review the evolution of radar technology, the relevant equations used in the interpretation of these data, and then summarize some of the published works where radar-estimated precipitation estimates are compared with rain gage measured data.

Radar technology has been helping weather forecasters in providing timely and useful rainfall forecasts to the public. Ever since RADAR (RAdio Detection And Ranging) was first used in the second world war to detect aircraft, the application for predicting weather phenomena (in particular, rainfall) has been fast maturing, both in the equipment used at the radar stations and also advances in the data processing software which analyzes the scanned radar data and processes them to arrive at precipitation estimates.

While every enhancement and upgrades, has provided with improvements in 
the estimation of precipitation quantities, a major technology development came with the advent of NEXRAD network (WSR-88D) which has proven to be a corner stone in modern weather technology. This evolution was primarily motivated by the need to detect severe storms and precipitation events. The WSR-88D is an offshoot of the advances made in Doppler signal processing theory, scientific knowledge of precipitation characteristics, advances in hardware capabilities and visualization software tools, among other factors. All these developments combined to provide a significant enhancement towards predicting precipitation quantities with a greater accuracy. The precipitation processing system in the WSR-88D was consequently deployed to enhance the flood forecasting abilities of several governmental agencies and private concerns. The works of Doviak and Zrnic [1]; Fulton et al. [2]; Smith et al. [3]; Serafin [4]; Whiton et al. [5], and the references in their works, provide deeper insight and rich resources for description of the NEXRAD system.

The Weather Surveillance Radar (WSR-88D) is the technical name for the 159 high resolution S-band Doppler weather Radar (see Figure 1) which are part of the NEXRAD (Next Generation Radar) network, and are operated by the National Weather Service. The WSR-88D radar operates by sending and receiving microwave pulses, in the $2-4 \mathrm{GHz}$ range, known as S band. Because the WSR-88D can estimate precipitation at high spatial and temporal resolution, it has high potential for hydrometeorlogical assessment including use in meteorological and hydrological modeling. The Doppler Radar transmits radio waves/pulses, at a rate of 1000 pulses/second, along a target path. These waves (when they hit the raindrop or hail or other interference) bounce back and a part of the transmitted energy is scattered back and received by the Radar receiver. This reflected signal is the result of the energy from the transmitted pulse interacting with cloud (cloud water and cloud ice) and precipitation (snow, ice pellets, hail, and rain) particles.

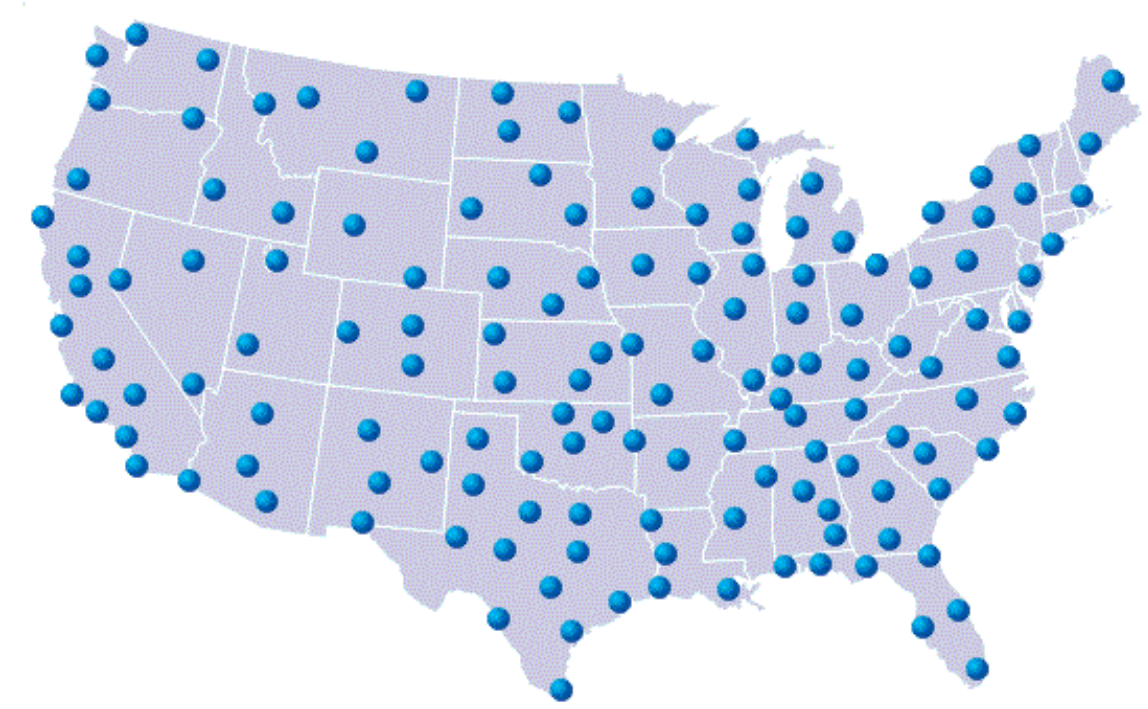

Figure 1. Locations of the WSR-88D RADAR sites in mainland United States [https://radar.weather.gov/]. 


\subsection{Mathematical Models Typically Used to Estimate Precipitation from RADAR Data}

The commonly employed formulation used in the estimation of precipitation from RADAR information is the Probert-Jones equation given by Probert-Jones [6]; Austin [7]

$$
p_{r}=\frac{C k Z}{r^{2}}
$$

where $p_{r}$ is the returned energy received back by the radar, $C$ is a parameter based constant (depends on transmitted power, beam width, transmitted energy wave length, antenna gain, pulse length, target character), $k$ is reduction in the signal attenuation along the propagation path, $r$ is the target range and $\left.Z=\sum D_{i}^{6}\right)$ is the "radar reflectivity factor", in which $D_{i}$ is the diameter of the raindrop interference.

The rainfall rate $(\mathrm{R})$ is estimated by using one of the empirical relationships that correlate Radar reflectivity and precipitation rate. These relationships have been derived largely based on measuring rainfall drop size as distributed in observed rainfall (Battan [8]). These relationships take the form of the usual power law given by $Z=A R^{b}$, where $Z$ is expressed in $\mathrm{mm}^{6} \mathrm{~m}^{-3}$ and $\mathrm{R}$ in $\mathrm{mm} \mathrm{h}^{-1}$. The relationships that are currently being widely used are $Z=300 \mathrm{R}^{1.4}$ (convective storms), $Z=200 \mathrm{R}^{1.6}$ (general stratified precipitation), $Z=230 \mathrm{R}^{1.4}$ (mixture of cellular and more widespread rain), $Z=400 \mathrm{R}^{1.3}$ intense convective storms, $Z=$ $100 \mathrm{R}^{1.4}$ (non-cellular rain). It is noted that these widely used equations, although all being power law formulations, differ considerably from each other, not only in their exponent values, but also in their coefficients. Consequently, variations in the precipitation event, over both time and across distance, as typically occurs, indicates potentially considerable differences in the outcomes of these equations in their predictions of precipitation.

\subsection{Evaluation of WSR-88D Performance for Estimating Rainfall}

Over the last two decades, many researchers have compared the WSR-88D precipitation estimates with actual precipitation gage observations and measurements and some of their findings are summarized below. Mizzell [9] compared the radar estimates of precipitation with measured values obtained from 62 standard rain gages and 10 tipping gauges, for storm events monitored in Lexington county in South Carolina. Her analysis examined 7 storms (1997-98 period) which spanned across a variety of storm types, such as convective storms, tropical systems, and stratiform events, showed that the radar data underestimates the precipitation, regardless of the storm type. The degree of underestimation varied with the intensity, type and duration of storm event. The deviation was highest for the stratified form and lower for convective storms. The limitations in radar to estimate accurate reflectivity due to hail, abundance of moisture in tropical maritime air, larger than average raindrop diameters and downdrafts were reasons for the underestimation. 
Skinner et al. [10] compared radar and precipitation gage measurements for time period of 4 years in the Southwest Florida Water Management District. While that study focused on the Upper and Lower Kissimmee river rain areas, the radar performance was evaluated across different seasons. Their analysis shows that the radar values are lower by $5 \%$, and the bias across the two data sets is present across all seasons. The authors state that the chosen Z-R relationship for converting reflectivity to precipitation rate plays an important role in the accuracy of the radar derived precipitation values.

Baeck and Smith [11] analyzed the radar rainfall values for five high flooding events, during the 1994-96 time period. While the radar underestimated the precipitation for four events, it overestimated the true value for one event. The errors in radar that caused the deviation are noted as being caused by, (a) the Z-R relationship, which is a function of the raindrop diameter; (b) radar overshooting at short distance and undershooting at far range; (c) the presence of hail which can lead to overestimates. Since few storms have both heavy rainfall and hail occurring at the same time and some other storms that have large hail and low rainfall rates, obtaining the correct reflectivity values from radar is a challenge.

Klazura et al. [12] compared the radar precipitation and precipitation gage values from 10 radar sites across 43 precipitation events. The events were classified into two categories; high reflectivity versus low reflectivity horizontal grade events. The accuracy of the radar values was tied to the precipitation category. While the radar significantly underestimated the precipitation data for low reflectivity events, it slightly overestimated the values for high reflectivity storms. For the former, the bias was more evident in short and long ranges. Possible reasons for the poor radar performance were reported to include anomalous propagation, inaccurate reflectivity values due to melting ice, bright band effects in stratified systems, presence of hail, and improper radar calibration.

Young and Brunsell [13] compared the daily gage date for the Missouri River basin with the radar Stage III and multisensory precipitation estimates. The overall bias for NEXRAD data was -39 percent for the cold season and -32 percent for the warm season. The mean bias in the radar precipitation values was $-38 \%$, which is greater than the values reported in some other reports in the literature.

Smith et al. [3] examined the issue of systematic bias by comparing the hourly precipitation derived values from radar gage data, across two radar sites for a 15 month time period starting from September 1991. They examined bias from three contexts and their data shows that their radar estimated precipitation values were inaccurate. Numerous issues were discussed with respect to biases relating to distance from the radar site. Range dependent bias was present for most of the events leading to incorrect precipitation estimates. While the precipitation was underestimated at low ranges due to incorrect reflectivity values at higher elevation angles, it was overestimated at intermediate range due to bright band and anomalous propagation. At long ranges, the values were underestimated due 
to overshooting. Their analysis showed that the rain gage observations were $48 \%$ higher than radar estimates in the range $0-40 \mathrm{~km}, 18 \%$ in the range $40-160$ $\mathrm{km}$, and $40 \%$ in the range greater than $160 \mathrm{~km}$ for the warm season. For the cold season the corresponding values were $30 \%, 14 \%$, and $100 \%$.

\subsection{Dual Polarization Radar}

The advances made in better understanding the science behind precipitation events has led to the upgrading the WSR-88D radars to Dual Polarization Radars. The dual radar polarimetry allows for data quality enhancements and addresses some of the limitations reported with WSR-88D radar. While WSR-88D radar transmits and receives radio waves along a single horizontal polarization, Dual Polarization radars transmit and receive signals across both horizontal and vertical polarizations. The availability of reflected power and phase details along two directions enables calculating additional parameters (eg, differential reflectivity, differential phase and correlation coefficient) which can then be used to arrive at improved precipitation estimates, and can better differentiate between heavy rain, hail, snow and sleet. The works of Zrnicand Ryzhkov [14], Doviak et al. [15], Bringi and Chandrasekar [16], Vaccarono et al. [17] provide more resources including precipitation equations relating to Dual Polarization or polarimetric radar.

\section{Errors in Radar Estimated Precipitation Values}

Villarini and Krajewski [18] provide a detailed examination of some of the errors associated in radar estimated precipitation values. The authors grouped possible errors into nine factors. While these are listed below, further details of that research investigation and descriptions of the identified noine factors can be found in the cited reference. These factors are radar mis-calibration, pulse signal attenuation, anomalous propagation, beam blockage, Z-R relationship adopted, effect of range, stratification of precipitation, movement of air in the vertical direction, and data sampling errors. Hunter [19] also presented an in-depth discussion of various precipitation estimation errors and considered possible potential remedies.

Krajewski et al. [20] quantified some of the uncertainties in radar precipitation estimates. Their analysis shows that although the radar estimates have improved over the last three decades, they noted that "Despite over 30 years of effort, the comprehensive characterization of uncertainty of radar-rainfall estimation has not been achieved".

Berne and Krajewski [21] discussed some of the challenges for the use of weather radar in hydrology (i.e., validation studies, precipitation forecasting, mountainous precipitation, error propagation in hydrological models). They noted that using weather radar for precipitation measurements in mountainous regions is still a challenge, since ground clutter, beam shielding and large vertical variability strongly affect the accuracy of estimates and need to be treated properly. 
In summary, the literature review shows that although it is true that Doppler radar has provided considerable increases in the understanding and assessment of storm precipitation and related weather phenomenon, these radar data and outcomes still require careful interpretation and further assessment in order to achieve a desired level of accuracy.

Recalling the title of the paper from the work of Berne and Krajewski [21], "Radar for hydrology: Unfulfilled promise or unrecognized potentia?" It is prudent, therefore, to continue data collection and conduct further assessment on the continuing evolving radar technology, but to carefully use these accumulating mountains of data with high levels of caution, with high attention to mathematical modeling computational error as well as collected and synthesized data measurement error.

\section{Doppler Radar Assessment Update for the Arid Regions of the County of San Bernardino}

The arid portion of San Bernardino County includes approximately 20,000 square miles of area, which are currently monitored by 77 precipitation gages with hourly or shorter duration data (excluding daily gauges). Based on the data from these 41 gauges, 156 storm dates with return frequencies estimated using the National Weather Service ("NWS") to be greater than 10-year were identified as occurring between years 1997 and 2015. We refer the readers to Hromadka et al. [22] that describes in detail, the step by step process used for identifying the acquiring the rainfall data for the candidate storms, their analysis, the used software modules from the NOAA weather and climate toolkit and assessment. To maintain continuity in the discussion, these are briefly reviewed here.

Since the arid region of San Bernardino County encompasses such a vast area, multiple radar Sites were analyzed for storm events. The Radar sites include: Yuma (KYUX), Edwards (KEYX), Santa Ana (KSOX), Las Vegas (KESX), and San Diego (KNKX). For the selected 156 storms dates, the one hour precipitation (LVL3) data was downloaded from NOAA website (http://www.ncdc.noaa.gov/nexradinv/) and the data animated using the NOAA weather and climate toolkit software. For each of the candidate storms, three days of data were obtained (when available). By including data for the day before the candidate storm, and the day after the candidate storm (target date of interest occurring in the middle), a more complete picture of the storm event (Figure 2) is rendered even if it begins in the evening of the previous day or continued through the night into the following day. From these animations, the 3-hr, 2-hr, 1-hr, 30-minute and 15-minute peak rainfall peak durations were identified. Based on the intensities for each target peak duration interval, the most significant storms (Figure 3) were identified for further analysis.

Some storms were eliminated from further consideration for one of the following reasons; (a) no Radar data available for the date, (b) available Radar data was corrupt, (c) no storm appeared on the Radar as being recorded at the rain 


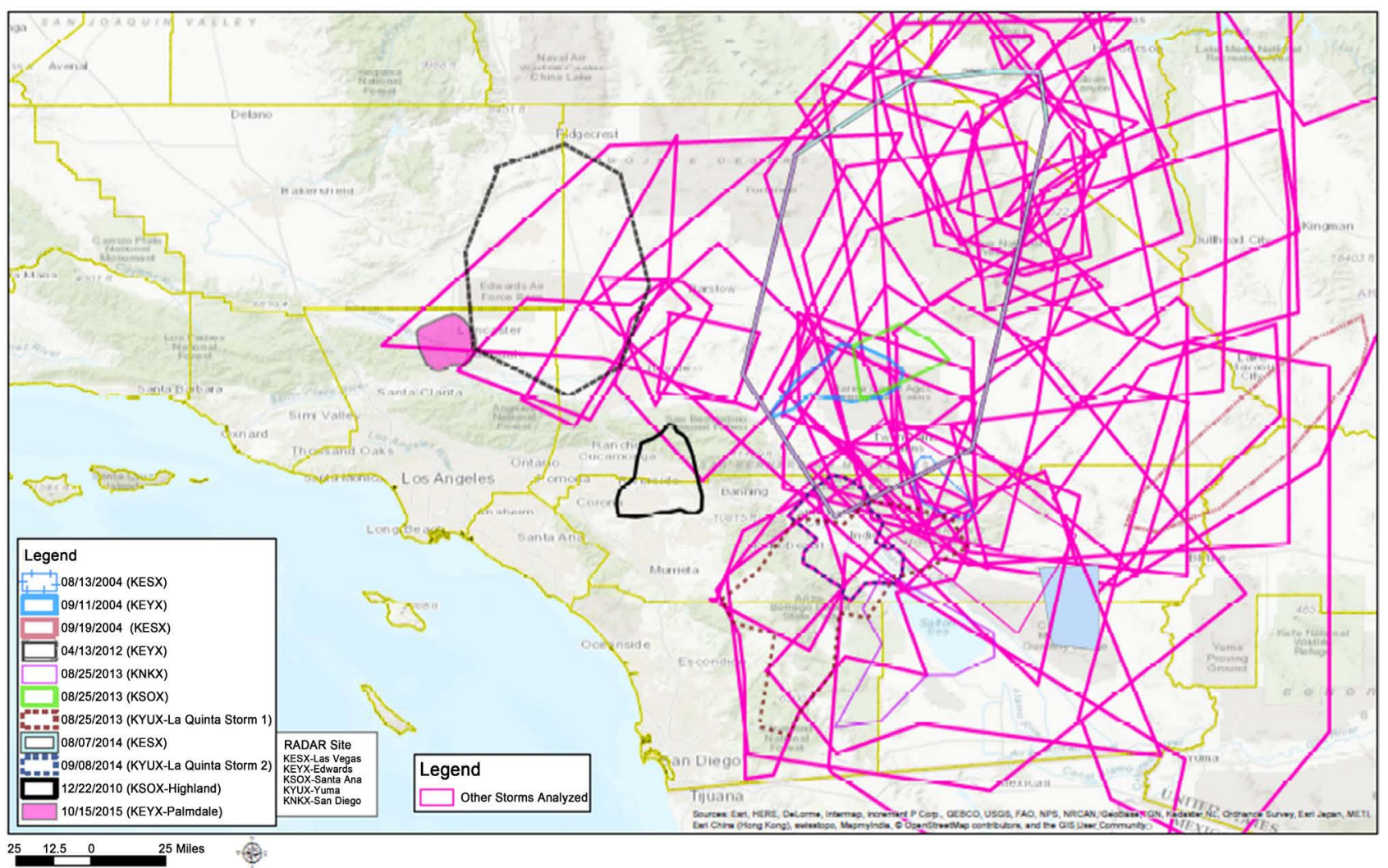

Figure 2. Analyzed storm locations during 1997-2015 period.

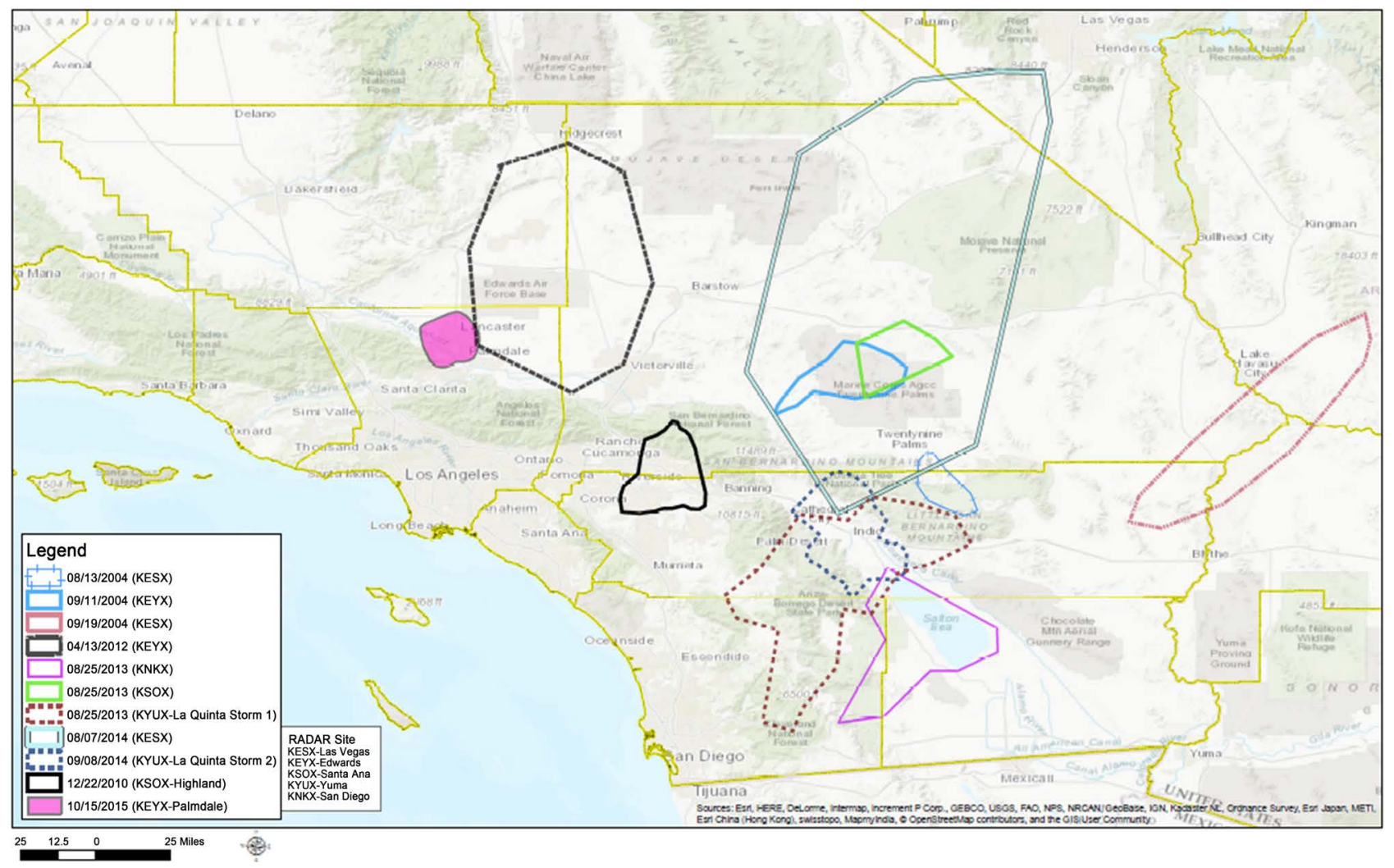

Figure 3. Key storm event radar aerial coverage locations. 
gauges, (d) the storm was not a top-ranking storm and (e) if same storm was measured on multiple Radar sites, the site with the best coverage was selected.

For the 1997-2015 period, by eliminating the storms based on above criteria, a total of eleven storms were identified as being significant. These storms (Figure 3 ) were examined at the peak 3-hour, 2-hour, 1-hour, 30-minute, and 15-minute durations. The 5-minute 1-hr intensity files were converted into accumulating depths for the given peak intervals. The accumulation grid files of the target peak durations for the said significant storms were then imported into GIS in order to locate the isolated storm cells and identify their areas of influence on a map. The estimated precipitation distribution depths were partitioned into intervals such that the number of instances with depth values greater than 0.1 , greater than 0.2 , greater than 0.3, and so forth, were recorded (using increasing increments of 0.1). This procedure continued until the maximum estimated precipitation depth value is reached. The number of instances for each partial value was then multiplied by a conversion scaling factor to derive an associated area in square miles (cell size). Using these values, an average normalized estimated precipitation depth for each target peak interval is calculated and the area extent versus estimated average precipitation depth for a given interval can be plotted (Figure 4).

\subsection{Comparison of Radar to Precipitation Correlations to Published Rainfall Depth-Area Curves}

To assess comparability between the derived Doppler vs estimated Precipitation correlation curves for the examined analyzed storm events, these Doppler vs

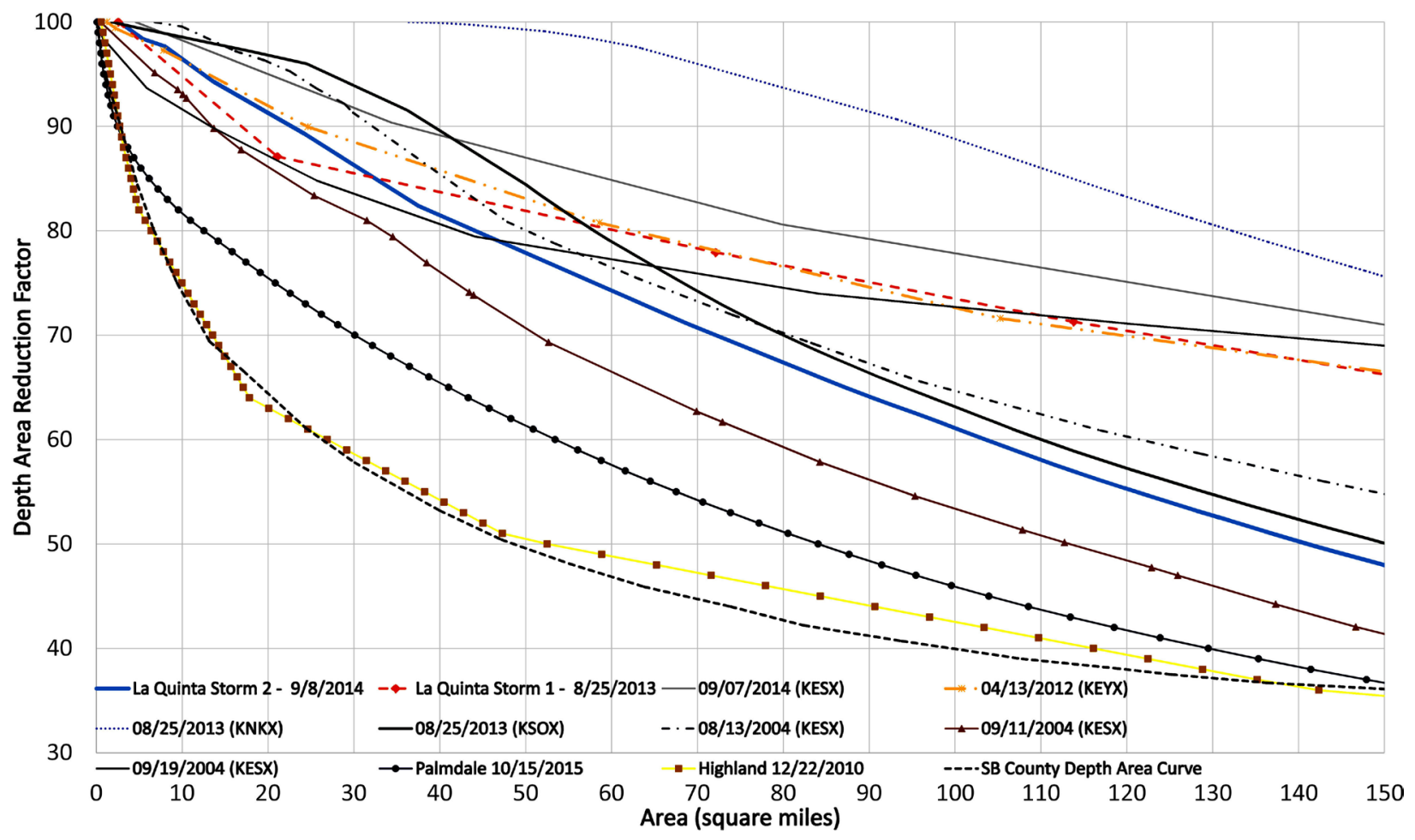

Figure 4. Comparison of Depth Area Reduction Factor for Key Storms (the storm details are listed in Table 1). 
Precipitation correlation curves were compared to the Depth-Area Adjustment Factor ("DARF") curves developed and published in various County Flood Control District Hydrology Manuals. The DARF curves published in the San Bernardino County's 1983 and 1986 Hydrology Manuals are based upon severe storm data including the Los Angeles area 1943 Sierra-Madre storm event as assessed by the US Army Corps of Engineers Los Angeles District office (USACOE). In comparison, the Riverside County Flood Control District (RCFCD) DARF curves are based upon the NOAA Atlas 2 that was published in year 1973. The RCFCD curves were originally published by the US Weather Bureau in year 1957, and are based on storm events that occurred in IL, IA, MO, NJ, NY, SC, and AL [23].

Other similar DARF relationships are available in the published literature and can be collected for comparison among other purposes. Such adjustment relationships were compared from the following agencies:

- Nevada Department of Transpiration (NVDOT) [24]

- Riverside County Hydrology Manual (NOAA Atlas 2) [25]

- Clark County Regional Flood Control District [26]

- Truckee Meadows Regional Drainage Manual [27]

- Maricopa County Hydrology Manual [28]

- Arizona Department of Water Resources [29]

A comparison of DARF values are shown in Table 1, and Figure 5, Figure 6, Figure 7, from the several considered agencies and from several of more significant storm events analyzed in the current study. It is noted that in the display

Table 1. Comparison of 1-hour peak duration precipitation depth-area reduction factors.

\begin{tabular}{|c|c|c|}
\hline 1H Comparison* & $50 \mathrm{mi}^{2}$ & $100 \mathrm{mi}^{2}$ \\
\hline 8/25/2013 (KNKX) & 0.99 & 0.89 \\
\hline 9/7/2014 (KESX) & 0.87 & 0.78 \\
\hline $8 / 25 / 2013$ (KSOX) & 0.84 & 0.63 \\
\hline 4/13/2012 (KEYX) & 0.83 & 0.73 \\
\hline 8/25/2013 (KYUX_La Quinta Storm 1) & 0.82 & 0.73 \\
\hline 8/13/2004 (KESX) & 0.80 & 0.65 \\
\hline Riverside County Manual (NOAA Atlas 2) & 0.80 & 0.73 \\
\hline 9/19/2004 (KESX) & 0.79 & 0.73 \\
\hline 9/8/2014 (KYUX_La Quinta Storm 2) & 0.78 & 0.61 \\
\hline 9/11/2004 (KESX) & 0.71 & 0.53 \\
\hline Nevada 90\% DOT (Vieux) & 0.68 & 0.55 \\
\hline 10/15/2015 (KEYX_-Palmdale) & 0.61 & 0.46 \\
\hline 12/22/2010 (KSOX_Highland) & 0.51 & 0.42 \\
\hline San Bernardino County Depth Area Curve & 0.50 & 0.40 \\
\hline
\end{tabular}

*The data is identified by the storm date and the radar site (KNKX-Sa Diego, KESX-Las Vegas, KSOXSanta Ana, KYUX_Yuma, KEYX-Edwards). 


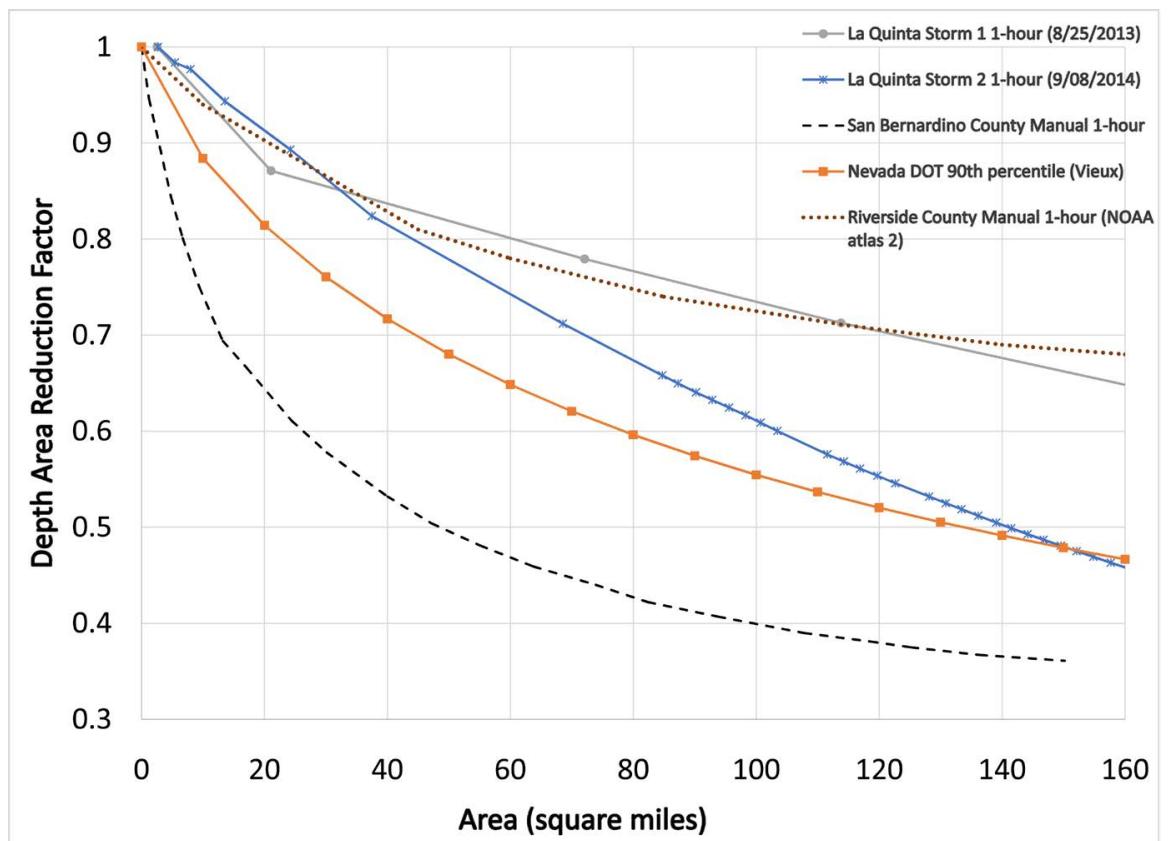

Figure 5. Comparison of 1 hour DARF curves.

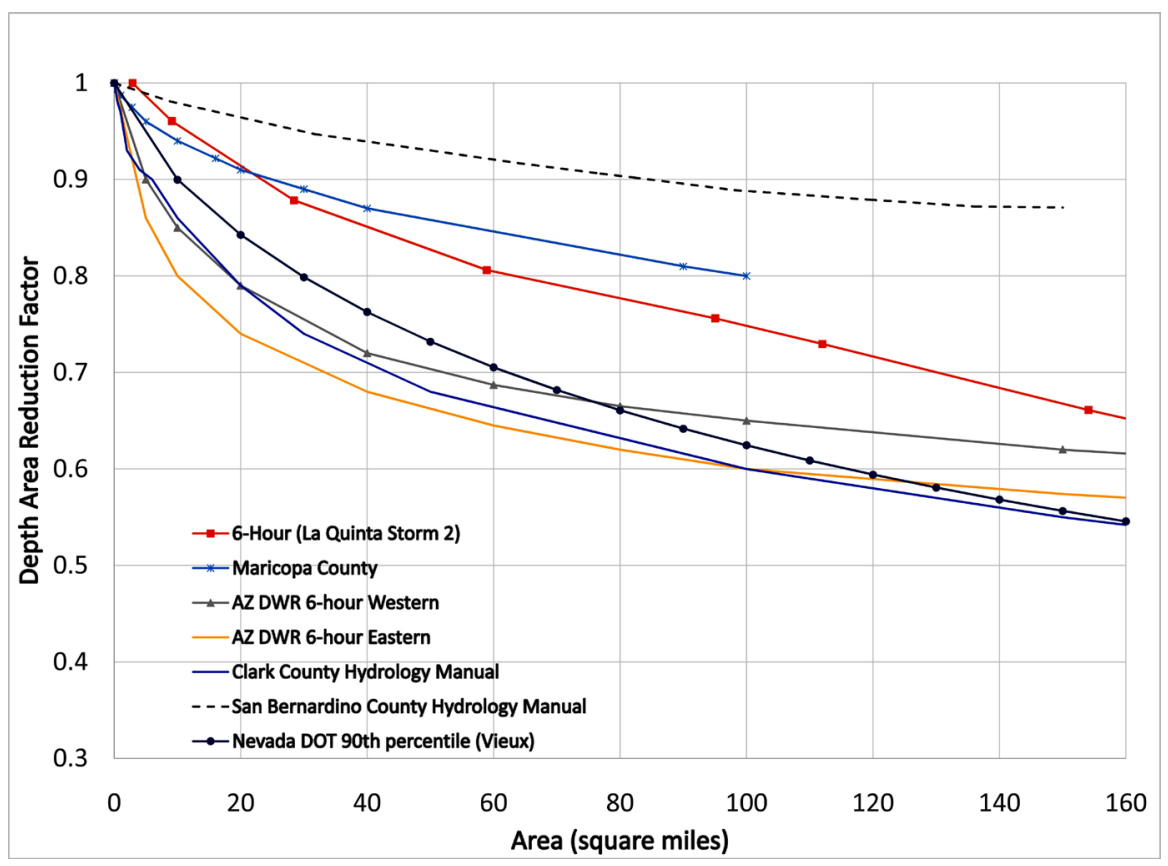

Figure 6. Comparison of 6 hour DARF curves.

of peak one-hour precipitation event data that arid severe storm events tend to have peak durations of approximately one hour.

\subsection{Stand-Out Arid Area Storms}

The La Quinta area of Southern California was subjected to two severe storms in successive years. Each storm was of remarkable rainfall intensity over approximately one hour durations. The second storm occurred in year 2014 with the 


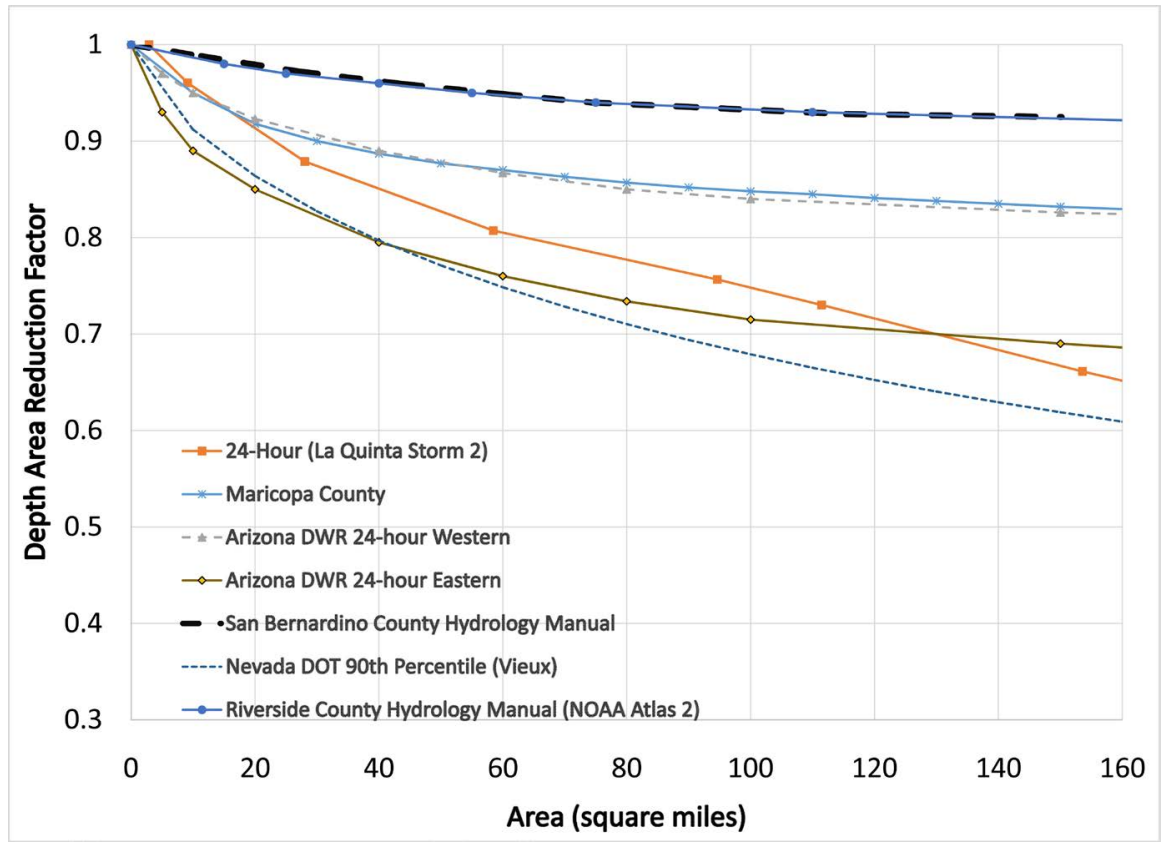

Figure 7. Comparison of 24 hour DARF curves.

first occurring in year 2013. Both storms caused significant flood damages, with the 2014 event being more severe and consequently, is displayed in the current paper. These are identified as La Quinta storm 1 (8/25/2013) and La Quinta storm 2 (9/8/2014) and briefly detailed below.

\subsubsection{La Quinta Storm 1 Details (Tropical Storm IVO)}

The remnants of Tropical Storm Ivo (8/25/2013) brought an influx of moisture into Southern California which resulted in heavy rainfall and flash flooding in the deserts of San Bernardino Riverside County. In the city of La Quinta more than 2.0 inches fell in a short period of time.

\subsubsection{La Quinta Storm 2 Details (Hurricane Norbert Storm)}

Hurricane Norbert (September 06, 2014) formed of the coast of south-central Mexico and moved northwesterly along Baja California where moisture from its remnants was pulled north (Figure 8, Figure 9). The remnants of the hurricane brought significant moisture to the southern portion of California, Nevada and Arizona. The circulation of Norbert along with the remnants of Atlantic Tropical Storm Dolly, spread moisture across northwest Mexico and into the southwestern United States [30]. Eight to eleven storm cells began to form in the Coachella valley, the migration propagated easterly to the Las Vegas area and then to Phoenix Area. Significant Rainfall occurred in Palm Springs and La Quinta Area. In Arizona 6.09 inches occurred near Chandler. At Phoenix Sky Harbor Airport during a seven-hour period 3.30 inches of rainfall occurred. It was also the largest daily rainfall in a single calendar day since records began in 1895 [31]. Approximately a third of Maricopa's County rain gauges set all-time records. 


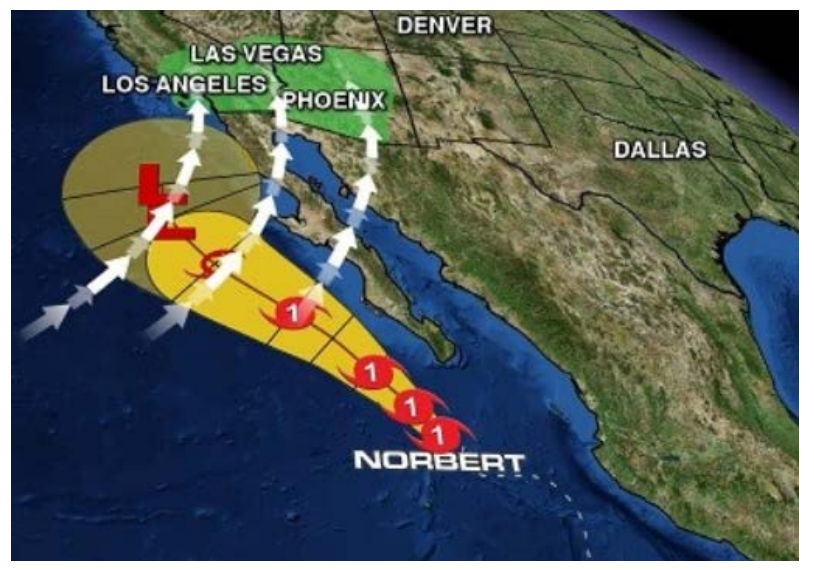

Figure 8. Path of Hurricane Nobert

(http://www.weathernationtv.com/news/hurricane-norbert-churns-in-pacific-potentiallybringing-flooding-rains-to-parched-desert-southwest/).

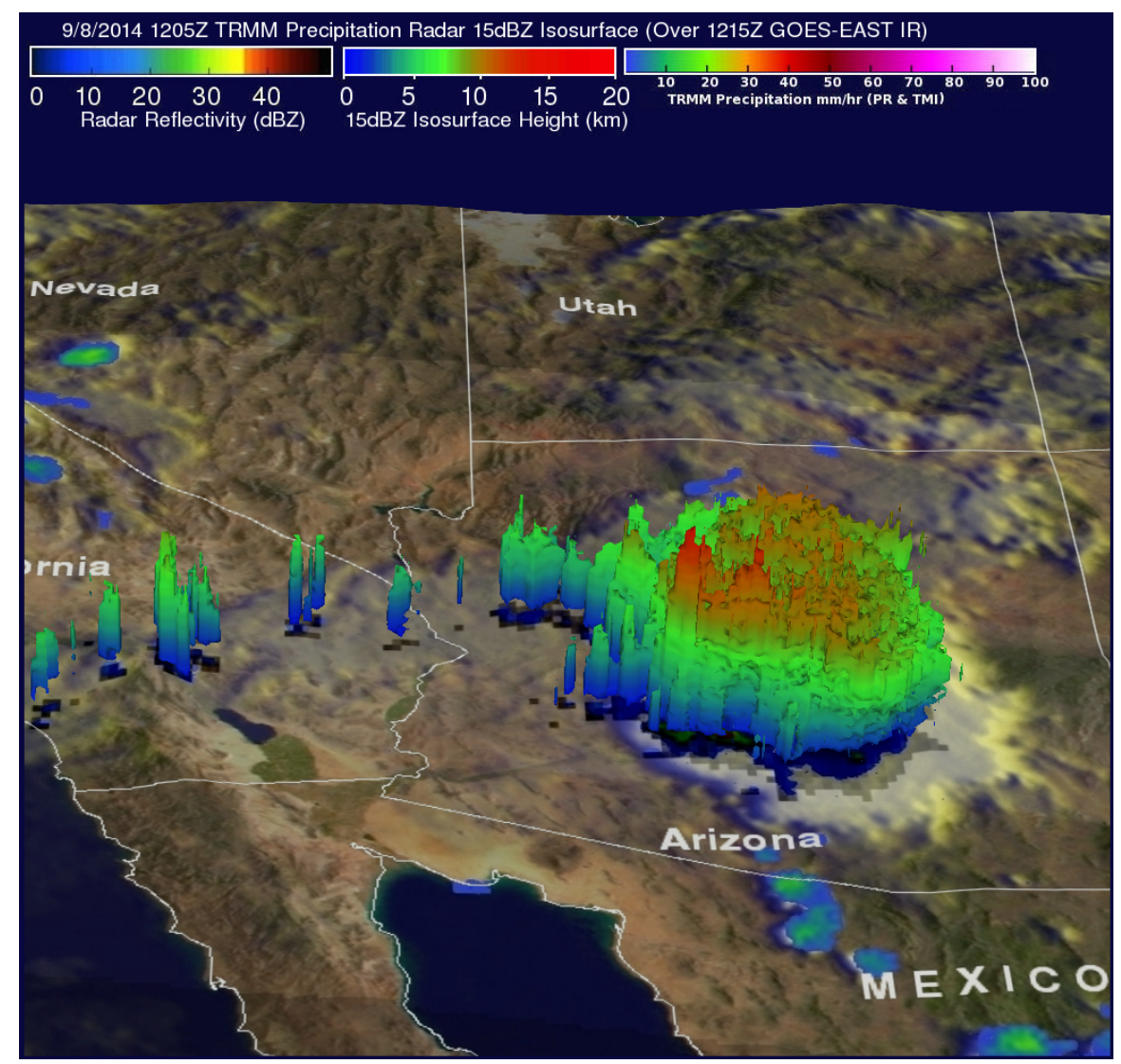

Figure 9. Thunderstorms produced by the remnants of Hurricane Norbert (https://www.nasa.gov/sites/default/files/arizona_storm_8_september_2014_1205_utc_tr mm_pr.jpg).

\section{Conclusions and Recommendations for Further Research}

In this study, the assembly and resolution of the many DOPPLER arid hydrology storm events has resulted in valuable information for use now and far into the future. Observed in this effort are at least two "stand-out" arid area storm events 
of particular interest. Namely, the years 2013 and 2014 storm events that are well documented in the La Quinta area, of Riverside County California. These particular storm events moved through the City of La Quinta area and also impacted the highly urbanized areas of Phoenix, Arizona and also Las Vegas, Nevada, among other arid areas (See Figure 9). These two large cities are the homes of the highly respected hydrometeorological monitoring and assessment Groups in the Maricopa County Flood Control District, and also the Clark County Flood Control District, respectively. A more recent storm event in October 2015 that delivered a remarkably high return frequency one hour precipitation event occurred in the Palm Desert area of the Los Angeles County Flood Control District. These Agencies published very high return frequency estimates for the subject 2013 and 2014 events of up to 900-year return frequency.

The comparison of the Doppler data based peak duration estimates versus estimated precipitation aerial extent, both variables estimated by the algorithms integrated into the NWS available information, and subsequent comparison with the published DARF curves in the relevant flood control agency Hydrology Manuals cited, suggests that an underlying correlation may exist. However, at this time, more data are needed to pursue this hypothesis, and therefore, such a conclusion would be premature.

\section{Note from the Funding Agency}

The County of San Bernardino Flood Control District's participation in the funding of this research was an academic exercise to understand the relationship between radar data and rainfall rates and must not be used for design considerations in the County of San Bernardino. The District has embarked on an aggressive program to install more rain gages in the arid regions of the County of San Bernardino which will provide more localized rainfall data for a future research project.

\section{Conflicts of Interest}

The authors declare no conflicts of interest regarding the publication of this paper.

\section{References}

[1] Doviak, R.J. and Zrnic, R.S. (1993) Doppler Radar and Weather Observations. Academic Press.

[2] Fulton, R., Breidenbach, R., Seo, J., Miller, D. and O'Bannon, T. (1998) The WSR-88D Rainfall Algorithm. Weather and Forecasting, 13, 377-395. https://doi.org/10.1175/1520-0434(1998)013<0377:TWRA>2.0.CO;2

[3] Smith, J.A., Seo, D.J., Baeck, M.L. and Hudlow, M.D. (1996) An Intercomparison Study of NEXRAD Precipitation Estimates. Water Resour. Res., 32, 2035-2045. https://doi.org/10.1029/96WR00270

[4] Serafin, R.J. (1996) The Evolution of Atmospheric Measurement Systems. In: Fleming, J.R., Historical Essays on Meteorology 1919-1995, American Meteorological Society, Boston, 43-56. https://doi.org/10.1007/978-1-940033-84-6_3 
[5] Whiton, R.C., Smith, P.L., Bigler, S.G., Wilk, K.E. and Harbuck, A.C. (1998) History of Operational Use of Weather Radar by U.S. Weather Services. Part I: The Pre-NEXRAD Era; Part II: Development of Operational Doppler Weather Radars. Weather Forecast, 13, 219-252. https://doi.org/10.1175/1520-0434(1998)013<0219:HOOUOW>2.0.CO;2

[6] Probert-Jones, J.R. (1962) The Radar Equation in Meteorology. Quarterly Journal of the Royal Meteorological Society, 88, 485-495.

[7] Austin, P.M. (1987) Relation between Measured Radar Reflectivity and Surface Rainfall. Monthly Weather Review, 115, 1053-1070. https://doi.org/10.1175/1520-0493(1987)115<1053:RBMRRA >2.0.CO;2

[8] Battan, L.J. (1973) Radar Observation of the Atmosphere. Univ. of Chicago Press, Chicago.

[9] Mizzell, H.P. (1999) Comparison of WSR-88D Derived Rainfall Estimates with Gauge Data in Lexington County, South Carolina: University of South Carolina, Department of Geography, Master's Thesis. http://www.dnr.sc.gov/climate/sco/Publications/thesis/thesis.html

[10] Skinner, C., Bloetscher, F. and Pathak, C.S. (2009) Comparison of NEXRAD and Rain Gauge Precipitation Measurements in South Florida. Journal of Hydrologic Engineering, 14, 248-260. https://doi.org/10.1061/(ASCE)1084-0699(2009)14:3(248)

[11] Baeck, M.L. and Smith, J.A. (1998) Estimation of Heavy Rainfall by the WSR-88D. Weather and Forecasting, 13, 416-436. https://doi.org/10.1175/1520-0434(1998)013<0416:REBTWF>2.0.CO;2

[12] Klazura, G.E., Thomale, J.M., Kelly, D.S. and Jendrowski, P. (1999) A Comparison of NEXRAD WSR-88D Radar Estimates of Rain Accumulation with Gauge Measurements for High- and Low-Reflectivity Horizontal Gradient Precipitation Events. Journal of Atmospheric and Oceanic Technology Issue In Progress, 16, 1842-1850. https://doi.org/10.1175/1520-0426(1999)016<1842:ACONWR >2.0.CO;2

[13] Young, C.B. and Brusnell, N.A. (2008) Evaluating NEXRAD Estimates for the Missouri River Basin, Analysis Using Daily Raingauge Data. Journal of Hydrologic Engineering, 13, 549-553. https://doi.org/10.1061/(ASCE)1084-0699(2008)13:7(549)

[14] Zrnić, D.S. and Ryzhkov, A.V. (1999) Polarimetry for Weather Surveillance Radars. Bulletin of the American Meteorological Society, 80, 389-406. https://doi.org/10.1175/1520-0477(1999)080<0389:PFWSR>2.0.CO;2

[15] Doviak, R.J., Bringi, V., Ryzhkov, A., Zahrai, A. and Zrnić, D.S. (2000) Considerations for Polarimetric Upgrades to Operational WSR-88D Radars. Journal of Atmospheric and Oceanic Technology, 17, 257-278. https://doi.org/10.1175/1520-0426(2000)017<0257:CFPUTO>2.0.CO;2

[16] Bringi, V.N. and Chandrasekar, V. (2001) Polarimetric Doppler Weather Radar: Principles and Applications. Cambridge University Press, Cambridge, New York. https://doi.org/10.1017/CBO9780511541094

[17] Vaccarono, M., Bechini, R., Chandrasekar, C.V., Cremonini, R. and Cassardo, C. (2016) An Integrated Approach to Monitoring the Calibration Stability of Operational Dual-Polarization Radars. Atmospheric Measurement Techniques, 9, 5367-5383. https://doi.org/10.5194/amt-9-5367-2016

[18] Villarini, G. and Krajewski, W.F. (2010) Review of the Different Sources of Uncertainty in Single Polarization Radar-Based Estimates of Rainfall. Surveys in Geophysics, 31, 107-129. https://doi.org/10.1007/s10712-009-9079-x

[19] Hunter, S. (1996) WSR-88D Radar Rainfall Estimation. Capabilities, Limitations and Potential Improvements. NWA Digest, 20, 26-36. 
[20] Krajewski, W.F., Villarini, G. and Smith, J.A. (2010) Radar-Rainfall Uncertainties, Where Are We after Thirty Years of Effort? Bulletin of the American Meteorological Society, 91, 87-94. https://doi.org/10.1175/2009BAMS2747.1

[21] Berne, A. and Krajewski, W.F. (2013) Radar for Hydrology: Unfulfilled Promise or Unrecognized Potential? Advances in Water Resources, 51, 357-366.

[22] Hromadka, T.V., Rao, P., Perez, R. and McInvale, D. (2018) Doppler Radar and Precipitation Depth Correlation for the Arid Region of San Bernardino County.

[23] US Weather Bureau, TP29 (1957) Rainfall Intensity Frequency Regime. http://www.nws.noaa.gov/oh/hdsc/Technical_papers/TP29P1.pdf

[24] Vieux, B.E. (2015) Radar Analysis for Design Storm Application. https://ams.confex.com/ams/37RADAR/webprogram/Paper275331.html

[25] Bryant, J.W. (1978) Riverside County Flood Control and Water Conservation District Hydrology.

http://rcflood.org/downloads/Manuals/Hydrology-Manual-20180814.pdf

[26] CCRFCD (1999) Clark County Regional Flood Control District, Hydrology Criteria and Drainage Design Manual.

http://gustfront.ccrfcd.org/pdf_arch1/HCDDM/Current\%20Manual\%20(Complete) /hcddm.pdf

[27] TMRDM (2009) Truckee Meadows Regional Drainage Manual. https://www.washoecounty.us/repository/files/7/tmrdm_final_043009.pdf

[28] MCHD (2016) Drainage Policies and Standards for Maricopa County, Arizona. http://www.maricopa.gov/DocumentCenter/View/2369/2016-03-Drainage-Policiesand-Standards-Manual-for-Maricopa-County-PDF

[29] ADWR (2017) Arizona Department of Water Resources. http://www.azwater.gov/azdwr/

[30] NOAA (2014) Hurricane NORBERT Bulletin Issued by the National Hurricane Center. https://www.nhc.noaa.gov/archive/2014/ep14/ep142014.discus.019.shtml

[31] NOAA (2014) Record Rainfall \& Widespread Flooding across Phoenix Metro Area. http://www.wrh.noaa.gov/psr/pns/2014/September/Sep8Flooding.php 